\title{
The Credibility Effect and Rational Expectations: Implications of the Gramlich Study
}

EDWARD GRAMLICH'S STUDY in this issue raises a question by a method that has frequently been found fruitful in scientific efforts. He presents an interpretation of observed data in terms of a widely used analytical framework that points to a very unfavorable distribution of the consequences of demand disinflation by undesirable output effects, on the one hand, and desired price effects on the other. Yet he directs attention to the possibility that a reconstruction of the standard framework could reduce the weaknesses he detects in the interpretation he presents. He does not favor the specific reinterpretation that $I$ have suggested in various writings ${ }^{1}$ and I will describe below-indeed, he leans perhaps more to an attitude of doubt in this regard-but he has an open mind about the methods of improving the conventional framework. Essentially, he plays into the hands of all those of us who are even more skeptical than he is about the conventional way of going about macroeconomic modeling and who believe in the superiority of a specific alternative. I would like to make use of the opportunity his work provides. This is done partly with reference to his empirical findings, to which I turn in the third section, after an attempt to place the matter in perspective.

\section{The Incomplete Overlap between Two Hypotheses}

Conclusions derived from analysis incorporating what may be termed the credibility effect overlap with conclusions from analysis commonly

1. For instance, in Fellner, Towards a Reconstruction of Macroeconomics: Problems of Theory and Policy (American Enterprise Institute, 1976). 
associated with the hypothesis of rational expectations. Both hypotheses lead to a critical attitude concerning essential features of the macroeconomic models most frequently used, but the two hypotheses need to be distinguished from each other. In this paper I briefly justify this statement and argue in favor of the hypothesis stressing the credibility effect. My conclusion is that once one eliminates the unconvincing elements from the rational expectations hypothesis, one is left with the credibility hypothesis as it is here interpreted. The hypotheses under consideration have the following main properties.

Standard models - The frameworks presently regarded as conventional explain the current wage and price increase of a period in large part by the preceding wage and price increase, though other variables such as the "slack," usually measured by the unemployment rate, also enter into the explanation. Expectations concerning future demand-management policy enter here merely implicitly through the assumption that-for any chosen value of other variables such as the slack-the past money-wage and price increases determine the current wage increases by unchanging coefficients. At the same time, in these models the current money-wage increases play a very large role in determining the current price increases, also by unchanging coefficients. Thus there is no room in the standard models for the hypothesis that a perceived change in the likely future conduct of demand-management policies-in the consistency of those policieswould alter the effect of past wage and price increases on the current increases, or would alter the current increases that become associated with any currently observed slack. Both the credibility hypothesis and the rational expectations hypothesis are critical of the assumption that the money-wage and the price trend are insensitive to the perceived policy posture, except insofar as that posture expresses itself in the currently observed slack given the other variables specified in the standard models.

The credibility hypothesis-The hypothesis of the credibility effect maintains that market expectations, and thus the effect of past moneywage and price increases and of any currently observed slack on current money-wage and price increases, are significantly influenced by the expected future behavior of policymakers. Emphasis is placed on the difference between states of the economy in which inconsistent policies lead market participants to form diffuse personal probability distributions with risk allowances playing a large role in their decisionmaking, and states of the economy in which firm and credible policies condition the public's ex- 
pectations and lead to much more strongly peaked and widely shared personal probability distributions concerning future events.

In particular, the hypothesis maintains that standard-model coefficients such as those estimated from Gramlich's wage-increase equation 1' would change significantly for the better-in the direction of a much more rapid reduction of inflation for any given slack-if a demand-management policy, which with brief interruptions was accommodative during a large part of his sample period, changed to a credible policy of consistent demand disinflation. This change in policies would have a major effect on price expectations, and the estimated coefficients would turn out to have overstated the effect of the lagged price and wage increases on the current increases. Allowance needs to be made for a transition period during which lags in establishing credibility, as well as past contracts and their temporary influence on new contracts, would continue to slow the process of price deceleration. But thereafter price deceleration would speed up substantially, the public's objectives being set in real terms.

For analogous reasons the hypothesis maintains that coefficients such as those of Gramlich understate the current increases in relation to the preceding wage and price increases for alternative levels of the slack if the authorities shift from a firm and credible anti-inflationary policy to one that accommodates inflation with minor and sporadic interruptions. Considering that during Gramlich's sample period (1954-77) a pronounced shift from credibility to laxity did in fact occur in this sense, the hypothesis suggests that during the sample period the deviations observed from the values predicted by the model should show a tendency to turn from negative to positive. ${ }^{2}$ In other words, along with the loss of credibility of the anti-inflationary policy posture, the given values of Gramlich's explanatory variables should show signs of becoming associated with steeper cost trends.

The rational expectations hypothesis-Views based on the credibility hypothesis overlap with views usually associated with the hypothesis of rational expectations. I am referring to a set of views as being commonly associated with "rational expectations" because there obviously exists no joint declaration of authors in such matters and because in some ways the views in question are still evolving. But to the extent that it is possible to speak of jointly held views of authors, I do not believe that the proposi-

2. Gramlich did not correct for serial correlation, which, I am told, was not found to be significant. 
tions I regard as characteristic of analysis based on the rational expectations hypothesis would misrepresent the views of the authors concerned. ${ }^{3}$ (It would be far-fetched to base an appraisal of the debate on a qualification to be described in note 4 below.)

The rational expectations hypothesis overlaps with that of the credibility effect, because both stress that the public is forming its expectations on the basis of all available information, including information on the probable future actions of policymakers. However, there are two reasons why the overlap is merely partial.

One reason is that the views commonly associated with the rational expectations hypothesis suggest that experience has in fact enabled the public to detect a system by which the authorities exert an influence on nominal demand, while the credibility hypothesis suggests that the public can detect such a system only if the authorities play effectively into the hands of the market participants by behaving consistently in an understandable fashion.

Consider, for example, a mode of behavior of the policymakers described by the accommodation of a so-called underlying inflation rate in order allegedly to stabilize that rate, and consider a policy that continues to accommodate inflation when the underlying rate steepens (as it will in such circumstances), yet becomes temporarily restrictive at some rate of acceleration-not the same rate on successive occasions. The latter mode of behavior illustrates game-strategy situations leading to highly volatile market expectations and to large risk allowances. This description fits the post-1965 policy posture of our authorities regrettably well. It cannot be expected to result in a state of the economy usefully described as one in which a system governing policy behavior has been figured out by the public.

Dependence of the suggested conclusions on the conditioning of market

3. For relatively recent contributions see, for example, Thomas J. Sargent, "Rational Expectations, the Real Rate of Interest, and the Natural Rate of Unemployment," $B P E A, 2: 1973$, pp. 429-80, and "'Rational Expectations': A Correction," $B P E A$, 3:1973, pp. 799-800; Thomas J. Sargent and Neil Wallace, "Rational Expectations and the Theory of Economic Policy," and Robert J. Barro and Stanley Fischer, "Recent Developments in Monetary Theory," Journal of Monetary Economics, vol. 2 (April 1976), pp. 169-83 and 133-67, respectively; Robert J. Barro, "Unanticipated Money, Output and the Price Level in the United States," Journal of Political Economy, vol. 86 (August 1978), pp. 549-80. References to the earlier contributions by John Muth and Robert E. Lucas, Jr., are found in these articles. See also note 4. 
expectations to a determined and well-understood demand-management policy is an essential part of the credibility hypothesis but not of the views commonly associated with the rational expectations hypothesis. This is one reason why the overlap is merely partial, but it does become a substantial overlap if situations are visualized in which market expectations have in fact been successfully conditioned to a consistent policy. According to both hypotheses, market decisions will be reached with a correct foresight of such policy behavior, which therefore will not lead the public to misjudge price trends and act as if it had money illusion.

The second reason why the overlap between the credibility and the rational expectations hypotheses is less than complete applies also to circumstances in which successful conditioning of market expectations to a credible policy line is taken for granted. With qualifications relating to the role of institutional rigidities, the hypothesis of rational expectations maintains that the correctly anticipated "systematic" component of the path of nominal demand affects merely the price level and has no influence on the real variables, but that the random deviations about that path, which can be foreseen neither by the authorities nor by the public, do have an influence on the real magnitudes. This is supposed to follow because the public sets its objectives in real terms and has figured out the effect of demand policies on the difference between "nominal" and "real." But the proposition involves more than this, and it therefore raises a number of bothersome questions that are-at best-partly semantic, and are avoided by the credibility hypothesis. ${ }^{4}$ For instance, the specific meaning of institutional rigidities raises such a question. The existence of these rigidities is known to the public, and in the reasoning of the rational expectations hypothesis

4. The possibility that some proponents of the rational expectations hypothesis might consider one or the other of the points to which I call attention noncontroversial (or "semantic") comes to mind mainly in view of conclusions formulated in Robert E. Lucas, Jr., "An Equilibrium Model of the Business Cycle," Journal of Political Economy, vol. 83 (December 1975), pp. 1113-44. On assumptions including limitations of information and of resource-mobility, (unexpected) shocks are represented there as generating "real" effects encountered during the business cycle, and it is suggested that the size of these disturbances does depend on the nature of the planned nominal path. Yet it cannot be claimed that the points discussed in the text above have been clarified by the proponents of the rational-expectations hypothesis. Also, it is difficult to see what beyond the credibility hypothesis would be supposed to remain intact if full allowance were made for these points. An appraisal of the present stage of the debate must imply that more or something different is intended to remain intact. 
they are relegated to the area of qualifications. The list of institutional rigidities that qualify the proposition would have to include not only those items that come most readily to mind for all real-world economies but even such items as the inevitable imperfections of all tax indexation schemes from which real tax effects are known to develop along any inflationary or deflationary nominal path. The list would have to include even the floor placed under the real rate of interest when a correctly anticipated nominal path involves a declining price level and when the nominal rate cannot decline below approximately zero. These should perhaps be regarded as at least implicitly admitted qualifications of the proposition asserting the "real neutrality" of the anticipated nominal path, but qualifications of such strength need to be faced directly and in some detail.

Another bothersome question is raised by the lack of sufficient clarity in many cases of the distinction between the real effect of the expected path of nominal demand (denied by the rational expectations hypothesis), and the real effect of random deviations about that path (recognized by the same hypothesis). This distinction is unclear in circumstances in which planned nominal paths and the size of the variance about them are known to be correlated. How is that distinction to be interpreted if the choice of an expected nominal path is known to involve greater variance about it than the choice of another, and the random variance about the nominal path has a long-run influence on the path of the real variables? Also, in such circumstances it is unclear why no real effect should be generated by the anticipated propensity of the demand-management authorities to move in one direction or the other at the unforeseeable date when the variance about the nominal path will start causing a noteworthy disturbance. Such interventions may be wrongly timed, and for this reason or for others they may cancel or be counterproductive, but that is a different question from the existence or nonexistence of a real effect.

At the present stage of the debate it seems to me far preferable to steer clear of these conceptual difficulties, and I will develop my argument in terms of the credibility hypothesis. This, too, involves rationality of expectations but does not include several of the propositions that have become associated with the hypothesis identified as that of rational expectations.

The remainder of this paper is concerned with two questions. The first relates to the conditions under which a credible policy of reducing the rate of increase of money GNP will result in disinflation of the price level 
and the restoration of a "normal" output path rather than in contraction of output combined with continued inflation. The other question is whether the results of the Gramlich study include indications that during part of his sample period consistent anti-inflationary policies generated a credibility effect that subsequently became extinct.

\section{Demand Disinflation and the Problem of Stagflation}

The discussion above does not imply by logical necessity that the authorities can gradually condition the public to the expectation of a practically stable price level. The reason is that the price level is not in itself a policy variable.

Demand management can show determination in its effort to reduce the rate of increase of money GNP from an inflationary rate to one compatible with practically noninflationary conditions, though even in this effort it may run into difficulties caused by unpredictable velocity effects. Assuming that these difficulties can be overcome-say, by playing safe in the direction of restraint-the remaining difficulty is that the market participants may become conditioned to expect continued price inflation coupled with a contraction of output, rather than a practically stable price level. This latter difficulty is hard to distinguish from that caused by the belief that in time the authorities will be forced to give up.

At this point the problem calls for taking into consideration some of the basic political and sociological characteristics of different countries. It is necessary first to ask whether a reduction of the rate of increase of money GNP to a level compatible with practically noninflationary growth will, in time, actually lead to such growth rather than to "chronic stagflation." If the answer is in the affirmative, it is also important to ask what determines the duration and the severity of the transition period.

In this discussion it is reasonable to assume that a group of market participants will fall in line with the objectives of anti-inflationary demand policies if it believes that most of the public will do so. This is the case because otherwise the group in question would be acting in the belief that its market power had risen, which should have been reflected in its behavior, regardless of whether a firm anti-inflationary policy had been adopted. The question therefore relates to the conditions under which a firm policy will lead the individual market participants to foresee that most 
other market participants will adjust their cost-setting practices. In that event, they individually also will be induced to do so.

The presumption is strong that in a country in which few believe that chaotic conditions will become prevalent for a long time, individual market participants will expect other market participants to fall in line unless a major part of the public adopts one of two views. The strategy will not work if it is widely believed that the authorities have an acceptable alternative to restoring practical price stability-such as the stabilization of an appreciable inflation rate-and if it is believed that at some stage the policymakers will shift to that course. Nor will the public tend to fall in line if it is believed that the authorities can and will rely on other methods for restoring price stability, thereby reducing their reliance on demand disinflation. My own diagnosis would suggest to me that most of the American public is on the way to recognizing that failure to restore price stability would have a highly detrimental effect because a reasonably stable inflationary growth path is a figment of the imagination; and that reliance on policies besides demand disinflation for restoring price stability will soon be recognized as unhelpful. These other methods consist of either incomes policies administered by votes-oriented democratic governments or comprehensive controls under authorities with greatly enlarged powers; and I believe it will not take long to convince most of the American population that these methods are unpromising.

Even those of us who believe that, in the United States, public opinion is changing to recognize that the authorities have no alternative to persisting in demand disinflation will have to anticipate a transition period with at least somewhat subnormal resource utilization rates. This is partly because it will take time to establish the credibility of a new policy resolve, and partly because long-term contracts involve a carryover of commitments for a limited period during which even the new contracts are likely to be somewhat influenced by the carryover. ${ }^{5} \mathrm{I}$ would find it astonishing if more than three to five years-say, the duration of a business cyclewere needed to establish the credibility of a truly consistent policy, and if the macroeconomically important aftereffects of long-run commitments lasted longer. This appraisal is consistent with the experience of several other countries that have recently succeeded in reducing their inflation

5. An analysis of this problem, with references to earlier contributions by Edmund Phelps and Arthur Okun, is found in John B. Taylor, "Staggered Wage Setting in a Macro Model," American Economic Review, vol. 69 (May 1979, Papers and Proceedings, 1978), pp. 108-13. 
rates from high to negligible levels, although differences exist in the nature of the difficulties that need to be overcome in different countries. In a related but not identical context to be discussed in the next section, Gramlich's data for the United States indicate about a five-year lag between the end of consistent demand policies aimed at price stability in the mid-sixties and the emergence of market behavior based on allowance for further acceleration rather than for any likelihood of a return to a noninflationary price trend.

\section{Implications of the Gramlich Study}

The credibility hypothesis leads to the presumption that, in a model such as Gramlich's, one is apt to find a tendency toward negative residuals - expressing an overestimate of inflationary increases-for the subperiod during which policies were aimed at practical price stability (1954-65). Because of lags in the perception of a change, one would expect to find negative residuals also for a limited period thereafter and to observe a tendency toward positive residuals-expressing an underestimate of the current increases-for the subsequent subperiod of lax policies. This expectation is confirmed for Gramlich's wage-increase equation, to which one would primarily apply this expectation; that equation at the same time avoids some difficulties inevitably encountered in his price-increase equation. ${ }^{6}$ The data suggest that after 1965 about five years elapsed before the public lost all traces of the pre- 1965 conditioning to policies aimed at price stability.

The residuals shown in table 1 were obtained by comparing the observed values of the wage increase to their estimated values derived with no correction for serial correlation. These estimated values are based on the actual values of the lagged explanatory variables. When the 1954-70 and 1971-78 periods are examined, the difference between the ratio of positive to negative residuals stands out. For these two periods the difference between the mean (algebraic) values of the residuals is significant at

6. The difficulties with the price-increase equation stem partly from the need to bridge the difference between adjusted average hourly earnings and labor compensation in the private nonfarm sector and the need to bridge the difference between the consumer price index and the private nonfarm deflator. Another major difficulty arises because the sum of the coefficients in the price-increase equation needed to be constrained in order to be consistent with one or the other of the unavoidably arbitrary assumptions concerning the ratio of prices to costs. 
Table 1. Actual Change of Money Wage Rates Minus Change Predicted by Gramlich's Equation 1', 1954-78

Percentage points ${ }^{b}$

\begin{tabular}{lc}
\hline Year & Residual \\
\hline 1954 & -0.6 \\
1955 & -0.2 \\
1956 & +1.6 \\
1957 & +0.7 \\
1958 & -0.5 \\
1959 & -0.3 \\
1960 & +0.1 \\
1961 & -0.1 \\
1962 & +0.3 \\
1963 & -0.2 \\
1964 & -0.5 \\
1965 & -0.4 \\
1966 & -0.2 \\
1967 & -0.5 \\
1968 & +0.1 \\
1969 & -0.5 \\
1970 & -0.2 \\
1971 & +0.3 \\
1972 & $0.0^{\circ}$ \\
1973 & $0.0^{\circ}$ \\
1974 & +1.3 \\
1975 & +0.6 \\
1976 & -1.1 \\
1977 & +0.3 \\
1978 & +0.6 \\
\hline
\end{tabular}

Source: Author's estimate of equation $\mathbf{1}^{\prime}$ in the Gramlich study.

a. The wage rates are average hourly earnings in the private nonfarm sector, adjusted to exclude interindustry shifts and overtime in manufacturing. The author added an estimate of the 1978 residual on the basis of data now available.

b. To be precise, differences between natural logs multiplied by one hundred.

c. Rounded from a positive number.

a level somewhat better than 10 percent in a one-tail test. Other indications point in the same direction. ${ }^{7}$

7. The 1971-78 period includes five years for which the preceding year's price increase-an important determinant of the current year's wage increase in the model -shows a steepening of inflation. For four of these five years the current year's wage residual was positive, suggesting that even more than the already steepened price increase entered the wage-determining process. Throughout that period no counterpart occurs in any negative wage residuals for years that were preceded by a reduced rate of price increase. Also, this observation is in sharp contrast with the behavior of the residuals during the 1954-70 period. 
I do not attribute much importance to this method of testing the credibility hypothesis because I would not be much influenced by a conventional significance test if it had less favorable results for the hypothesis. By its choice of the null hypothesis, the conventional test gives a huge benefit of the doubt to the highly unconvincing assumption that in recent years the public has not changed the way in which, given the other specified variables of a standard model (in Gramlich's case, given only the current slack in the economy), current wage increases develop from past price and wage increases. In Gramlich's wage-increase equation even a substantial benefit of the doubt given to this implausible assumption is overcome by the behavior of the residuals. Yet regardless of this, it would be astonishing if the wage-moderating effect associated with a given slack were identical under two circumstances: (1) when the authorities are firmly expected to give high priority to the demand-policy restraint needed to fight any past steepening of price increases and (2) when unemployment-rate targets are expected to become dominant soon again, even at high rates of inflation.

In conclusion, it should be stressed that the widely used regression technique is not particularly dependable, and one should not look for final answers in any of the available models. I am sure Gramlich and I would agree on this and so would (or should?) practically all economists. So far as the model discussed above is concerned, it does provide indications of differences between the 1954-70 and the 1971-78 periods in the way in which price expectations and therefore actual wage trends were related to past price and wage experience. Considering that price history would suggest that the break should have come soon after the middle of the 1960 s, these indications point to a lag of a few years before the full realization of a major change in the conduct of demand policy.

But leaving specific models aside, it is possible to tell the story differently than I have, and to place almost the entire emphasis on the weight of past heritage on the evolution of current events. This is what standard models are in fact doing. Yet what in Bayesian theory are called one's priors cannot be disregarded in these matters, and it is necessary to decide whether to give the benefit of the doubt to the assumption that the process of determining wages and prices is mostly backward-looking or, alternatively, to the assumption that the process appears to be so only if policymakers are expected to continue accommodating past first or higher price derivatives with occasional interruptions. I find the second of these two 
ways of looking at the problem much more convincing, and thus I believe that coefficients such as that estimated by Gramlich would change significantly under a firm policy. But while I suggest strong indications of a credibility effect in the data, I do not believe that the matter will be decided at the level of regression analysis.

\section{The Public's Acceptance of Demand Disinflation}

Gramlich and others have rightly stressed that, in a democracy, policies must be acceptable to the public. As I said above, I base my views about the future of demand disinflation on the belief that the time is approaching when the public will be convinced that the temporary difficulties associated with consistent disinflation are inevitable. I believe we are not far from there, even if we may not yet have arrived quite at that point.

As for Gramlich's interesting and original analysis of variables determining whether the public, when polled, regards inflation as more troublesome than unemployment or vice versa, I doubt that the results bear closely on the problems discussed here. If, in definable circumstances, a person says that at present he considers unemployment the more troublesome problem, I do not interpret his answer as logically implying that he is agreeable to efforts by which unemployment is temporarily reduced at the expense of more inflation. He might be well aware that, if the authorities undertake such efforts, then he will soon say that inflation has now become the more troublesome problem. To use an analogy, if a person running a high temperature is taking antibiotics that make him feel uncomfortable, then, as the fever is reduced, he will at some point truthfully say that the discomfort caused by the medicine exceeds the discomfort caused by the fever. Yet while the problems involved in such points of indifference are worth exploring, it fortunately does not follow that such a person will refuse to take antibiotics. 


\section{Comments and Discussion}

Edmund S. Phelps: Edward Gramlich's skillful and provocative paper presents an econometric assessment of the benefits and costs entailed by a monetary policy of "accommodating" supply shocks. For Gramlich and others, a policy of accommodation means adjusting the money supply in response to the unanticipated supply shock in such a way that the unemployment rate is equated (perhaps with some unavoidable lag) to its previous value or perhaps its previous target value. In my paper on supply shocks, a policy of accommodation means adjusting the money supply in such a way that the unemployment rate is equated (in the expected value sense) to its equilibrium value; by that I mean that the unemployment rate is kept to a level at which wage setters are glad they set the moneywage rates they did (rather than lower rates, as would be the case if the monetary policy were to allow employment to slump in response to the supply shock). Thus the central bank reinforces the pattern of wage expectations, and the resulting path of realized wages, that it seeks to instill.

The particular accommodative monetary policy envisioned in my paper is one that encourages the expectation on the part of wage setters that the average money wage will "track" from period to period some predesignated trend path-either a flat path or a regularly rising path. Consequently that policy never creates the expectation of a deficiency of the derived aggregate demand for labor at the "programmed" money-wage level-as would be the case if the money supply were expected to be unbending in response to a drop in the marginal money-value productivity of labor caused by a supply shock; if monetary policy did that, it would be inviting a sag of money-wage rates below the programmed time path. But the accommodative policy would allow employment and output to 
suffer if and when money-wage rates somehow strayed above their programmed path. In a paper I wrote with John Taylor, consideration is given to a variant of this plan: when the average of money-wage rates deviates from the old programmed path, the economy is appropriately penalized with deficient (or excessive) employment, so that wage setters will not think that they can with impunity entertain arbitrary expectations of what the average money wage is going to do; but today's deviant wage constitutes the new base from which the newly programmed growth path of planned money wages now originates.

Is this program not as fine a vision as any of the good macroeconomic life? Yes, there is Milton Friedman's caveat to reckon with: by striving to realize this program too exactly, we might on average make things worse, not better. So some compromises might have to be made on this score. But other than that, what is wrong with it? Yes, there is the additional point that the price level will follow a random walk process (assuming that supply shocks are independently distributed). And even the trend rate of inflation will shift with sea changes in the rate of productivity growth. But the alternative is that money wages follow a random walk and even suffer occasional shifts in their trend rate of growth. Why is the latter policy option superior to the former?

No less an economist than John Maynard Keynes, as I finally remembered, had come down on the side of a wage standard as the best guide for monetary policy. And even The Wall Street Journal extolled West Germany in a recent editorial for its pursuit of a wage standard (rather than an employment standard). It makes some sense to try to stabilize the price that is determined in the most imperfect market, letting prices determined in perfect markets be free. Presumably the labor market is typically less perfect than the product markets, so from this point of view it is the average money wage that is the best candidate for stabilization (around a predesignated trend path).

Gramlich's paper expresses a number of reservations on his part about the desirability of the Keynes-Phelps vision. A highly accommodative policy scores worse than a policy of price-level stabilization (and especially worse than a policy of nominal-income stabilization) if the welfare cost imputed to variability of inflation is sufficiently large compared with the welfare cost of variability in employment-the more so the smaller the social rate of discount, and the more so the more expansionary the current policy relative to the restraint required to accord with the public's pref- 
erences. But doesn't Gramlich load the dice by focusing on the variability of the actual rate of inflation instead of the variability of the expected rate of inflation, which is presumably far more stable? If it is movements of the actual price level that people do not like, anticipated or unanticipated, why should a worker hate to see a doubling of the price level over ten years more than a halving of his money wage over that same time? If the representative worker's dislike of variability in the price level is just his way of expressing dislike of variability in his real wage, then giving him a harshly nonaccommodating monetary policy could hardly make him happier because it could do little to stabilize his real wage and much to destabilize his real earnings.

The concept of accommodation in Gramlich's test is different from constancy of the money-wage path because of his introduction of the positive $a_{3}$ term in his equation 1 -that is, the feedback of past price inflation on the current rate of wage inflation given the past rate of wage inflation. If I am not mistaken, a highly accommodative policy in Gramlich's conception tends to maintain the rate of unemployment; so a one-shot increase of the price level (through the feedback onto wages and the latter's effect back on the price level) leads to an indefinite lift of the rate of inflation and, correspondingly, the rate of increase of the money wage. But that is hyper-accommodation compared to the more modest proposals of Keynes and me. Does Gramlich's policy of cold turkey beat the warm beer of constant money wages (or regularly rising money wages) as advocated here-when there is the price-wage feedback? The latter contestant would be less easy to beat than Gramlich's accommodative straw man. Before leaving this topic I ought to say that the presence of past inflation in an expectational theory of the Phillips curve is debatable at best; but one might think of this factor as attributable to escalator clauses in wage contracts of two or more years. I concede that I left that factor out of consideration in the formal part of my analysis of supply-shock accommodation; but see, however, the extensive informal discussion of the matter at the close of my paper.

One last point: Gramlich's analysis of the staggered-contract model with rational expectations, with which he concludes his paper, leads him to the proposition that the effects of a supply shock on employment are entirely extinguished in finite time-after the contemporaneously extant contracts have all expired-even when monetary policy is completely passive, for example. This property of Gramlich's model leads him once 
more to downgrade accommodation-it is only needed temporarily anyway. But this property does not emerge from the world of unindexed overlapping contracts studied, for example, by John Taylor and me. There the traces of a shock last forever unless erased by an activist monetary policy or else covered over by some new shock.

Robert J. Gordon: The "positive economics" of supply shocks seems now a well-established and relatively uncontroversial part of macroeconomics. For any given growth rate in nominal GNP, any event that shifts upward the short-run inflation-unemployment trade-off curve will alter the division of the change in nominal GNP between inflation and growth of real output. To maintain the previous inflation rate, nominal GNP growth must be slowed. To maintain the previous unemployment rate, an accommodative acceleration in nominal GNP growth must be allowed. In early 1974, Phelps and I predicted that the OPEC oil shock would cause a recession if nominal GNP growth followed the widely forecast path, and I added that the price rebound following the end of controls would aggravate the downward pressure on real output.

The main substantive question remaining in the positive economics of supply shocks is the same as that originally identified in that early literature: how will the expectations of future inflation by firms and workers respond, a question that naturally depends on whether the shock is thought to be transitory or permanent. In the face of a permanent shock, the "natural" level of output is permanently reduced, and employment will also be reduced during a potentially lengthy adjustment interval, depending on the flexibility of the real wage.

In contrast to this straightforward analysis, the "normative economics" of supply shocks-what policymakers should do-is a difficult and highly controversial area, and it is here that Gramlich's paper makes its main contribution. Ironically this topic, the welfare economics of inflation and unemployment, has nothing intrinsic to do with supply shocks, and most of its literature antedates the shock episode of 1974. But a full discussion of this policy trade-off is more relevant than ever in 1979. Not only have we had three visible and widely discussed adverse supply shocks -in the form of increased relative prices of food and oil and of government price-raising policies (minimum wage, payroll tax, and others)but also the slowdown in aggregate productivity growth creates yet an- 
other shock if the ability of firms to pay higher real wages decelerates relative to worker aspirations for higher real wages.

One weakness of Gramlich's paper is that it contains too much. Every alternative is considered, presenting an enormous number of permutations of policy responses. Without whittling down his menu of possibilities, the reader really is left in the dark about when policy should deviate from the basic recipe of complete accommodation. The answers depend on (1) whether the long-run trade-off is vertical, (2) whether wages depend partly on past prices or just on past wages, (3) whether the short-run Phillips curve is steep or flat, (4) whether the parameters are affected by government policy, (5) whether the public fears inflation or unemployment more, (6) whether the future is discounted at a high or low rate, and (7) whether the supply shocks are serially correlated.

Let me begin by questioning Gramlich's eclecticism on the long-run trade-off. I conjecture that his nonvertical long-run curve results almost entirely from his use of the consumer price index (CPI) on the right-hand side of the wage equation. In my paper in $B P E A, 2: 1972$, which provided a battery of sensitivity tests on this and other issues, it was clear that George Perry's choice of the CPI always led to a lower sum of coefficients on lagged prices in the wage equation than the alternative of using the personal consumption or private nonfarm deflator. In statistical terms, the CPI contains measurement error due to its treatment of mortgage interest rates and food prices, and thus its coefficient tends to be biased toward zero. Acceptance of a vertical long-run trade-off curve helps reduce Gramlich's overly large menu of possibilities not only directly, but indirectly by throwing out two of his seven estimates of the parameter, $b$, those labeled "revealed preference."

The long-run trade-off problem can be expressed another way. I have recently compared the results obtained from the estimation of separate wage and price equations and of a single reduced-form price equation. The long-run trade-off coefficients in the two-equation approach seem quite sensitive to the particular choice of the wage and price data, whereas the single-equation approach seems quite robust in its finding that the long-run trade-off is vertical.

An example of the pitfalls of running separate wage and price equations is illustrated by Gramlich's handling of the results of measurement error. He finds that the sum of lagged coefficients in the wage equation 
falls short of 1.0 but in the price equation exceeds 1.0. His asymmetric remedy is to constrain the latter equation but not the former. Neither or both should have been constrained, and better yet, all results should have been cross-checked by fitting the single reduced-form price equation directly.

The size of the price feedback on wages is a crucial item on the menu of possibilities, because it governs the response of real wages to supply shocks. One aspect is the point made by Robert Lucas and by William Fellner in his report in this issue: parameters shift in response to policy. Fast inflation has substantially increased the share of wage contracts that are formally indexed, and thus the lagged price coefficient in the wage equation should be expected to be higher in the 1970s than it was in the 1950 s and early 1960s. Part of the rapid increase of wages in 1974 resulted from the escalator response to oil, food, and "end-of-controls" inflation.

A second problem is Gramlich's refusal to constrain his "post-controls rebound" dummy variables to have a coefficient exactly equal in absolute value (but opposite in sign) to his initial controls dummies. Because the procedure allows a free dummy variable coefficient in 1974-75, while preventing the price-wage feedback coefficient from varying in response to the increased importance of indexing, Gramlich's results are likely to understate the size of the price-wage feedback coefficient.

The heart of the paper is the normative analysis: what is the welfare loss caused by differing degrees of accommodation? Here the wide range of estimates of $b$ is disconcerting. The largest estimate, $b=4.0$, comes from the constrained Gallup poll. While I am convinced that the constraint is sensible and that the results in table 1 should be ignored, I am nevertheless skeptical of the use of poll data for this purpose, for several reasons.

First, answers to the inflation question do not tell us anything about the "pure" effect of inflation. People see inflation eroding their real income; however, in their answers they do not consider the numerous offsetting effects of inflation that are known to economists in classrooms but not to shoppers in grocery stores. Inflation tends to raise prices now and wages later, creating a real wage effect that is transitory. Inflation cuts the value of nominal assets, but families do not realize that corporations and governments gain and are able to use their gains to reward consumers, workers, stockholders, and taxpayers (in this sense the "robbery" analogy 
is extremely misleading). The final deadweight loss from inflation is much smaller than the gross amounts shuffled around among groups in the economy, and many of its redistributive effects could be eliminated by the types of policies Gramlich does not consider-for example, the deregulation of financial institutions and the issuance of an indexed government bond.

Second, the man in the street similarly exaggerates the effect of unemployment; in a period of rising unemployment, he begins to worry about losing his job, even though his income may remain unaffected. This "extrapolative fear effect" should be ignored by omniscient policymakers, who for any given supply shock should be able to predict that nonaccommodative policies will increase unemployment by only a finite amount.

Third, Gramlich's interpretation of the Modigliani-Papademos study appears to accept an obsolete estimate of the Okun's law coefficient (3.0), and to ignore the distinction between temporary and permanent increases in unemployment. The so-called Okun's law puzzle of 1978 is resolved in an unpublished paper by James Glassman, who shows that the dramatic decline in unemployment in the $1975-78$ period can be explained by a deceleration in potential GNP growth corresponding to slower secular growth of productivity and by the finding that the Okun's law coefficient is actually 2.0 , not 3.0 .

The long-run effect that brings down the Okun's law coefficient occurs as firms begin to adjust to lower employment by eliminating idle plant and idle overhead workers, and the distortion in hours per worker. In 1973, I argued (BPEA, 1:1973) that, for the long run, the Okun's law coefficient is actually less than 1.0 , as optimum plant sizes, overhead workers, and hours are adjusted to the new situation.

Fourth, a related factor ignored by Gramlich is that the long-run growth rate of potential real GNP should enter the social welfare function. The cutback in the investment-GNP ratio during the typical recession permanently endows society with a lower capital stock, while higher inflation combined with a nonindexed tax system creates offsetting (Feldstein-Summers) disincentive effects. I believe that the long-run effects on the capital stock of a given increase in unemployment dominate those of an equal percentage-point increase in inflation, but I cannot convert this conjecture into a "proof" at this time.

My conclusion regarding the value of $b$ is that the poll results are more likely to overstate the harm done by inflation than that of unemployment, 
and that an appeal to a priori economic reasoning would probably yield a $b$ estimate closer to 4.0 than 1.0 , supporting a relatively accommodative policy stance.

Finally, let me report some results that cast doubt on the Fellner credibility hypothesis. In equations explaining price change, a contest was held between lagged inertia terms and measures of expected policy a la Barro. The results strongly suggest that the response of prices to policy expectations in the 1954-78 period was essentially zero, and that the inertia effect dominates. This econometric result corresponds to reality, as I see it. Does Fellner really think that a strong speech by President Carter or Chairman Miller of the Federal Reserve would have led the airline machinists to ratify rather than reject an already inflationary settlement? The attitude of the public toward government statements is skeptical; agents know that a new administration in 1981 might reverse any present deflationary resolve. The public's attitude is rightly "we'll pay attention to what you achieve, not to what you say." The difficulties of the United States in this regard are contrasted by Fellner to the faster response of inflation to anticipated policy in some other countries, but here I think he overlooks the pernicious role of our decentralized and staggered wage-bargaining system and the difficulty of changing that institution.

\section{General Discussion}

Lawrence Krause urged that Gramlich's analysis be extended beyond the closed-economy perspective of the paper. Once international aspects are recognized, it becomes clear that a supply shock might have important effects on the terms of trade and on external asset and debt positions and that the U.S. policy response might have significant international feedbacks. In particular, Krause felt that the appropriate policy response to a supply shock that improved the terms of trade and raised real incomes, like a Russian crop failure, might be very different from the response to a shock that lowered real incomes, like the formation of OPEC. But Gramlich doubted that the nature of the change in relative prices would alter the appropriateness of accommodation or nonaccommodation by macroeconomic policy.

William Poole shared an aspect of Krause's concern about equating all supply shocks. He called attention to positive shocks, like the U.K. dis- 
covery of oil in the North Sea. In his judgment, the appropriate response to a major strike that produced disruptive effects in other industries might well differ from a response to an agricultural shortfall. Nor was it obvious to him that the proper policy response should be the same to governmentinduced shocks as to truly exogenous ones. For example, both a withdrawal of land from production mandated by the government and a crop failure due to the weather would raise consumer prices; but these two events do not necessarily point to identical policy adjustments.

Much of the discussion was related to Gramlich's assessment of the relative costs of inflation and unemployment. James Duesenberry and Lawrence Summers argued that the respondents to Gallup surveys might fail to take account of subtle social costs of inflation. Duesenberry mentioned the costs of the social frictions that resulted from the need to change certain politically determined prices and tax schedules, and he noted the effects of rapid and variable inflation on economic stability resulting from the encouragement of speculative activity and the need for international adjustment. Summers pointed to the distortions of capital accumulation resulting from the effects of inflation that operate through the tax system. Duesenberry emphasized equally that the social costs of unemployment, which operate by harming job and promotion opportunities for minorities, might not be adequately reflected in the responses obtained by Gallup. Unemployment can be quite costly, even if most people are not affected by it. Arthur Okun remarked that, in responding to opinion surveys, people put much more weight on unemployment when asked whether it was a serious problem for the country than when asked whether it was a serious problem for them personally.

William Brainard argued that Gramlich's procedure involves double counting. Individuals presumably incorporate in their responses some expectations about the likely duration of unemployment and inflation and have already done the summing. Experience tells them that inflation is longer lasting than unemployment; therefore they respond more strongly to bad news of inflation. Hence, using their responses to weight the variables each period and then summing over periods is likely to overstate the relative costs of inflation.

Brainard also questioned Gramlich's choice of the interest rate to discount the future costs of inflation and unemployment. The after-tax interest rate of lenders did not seem particularly relevant for people affected by unemployment. 
Recognizing the limitations and problems that others had highlighted, Peter Kenen nevertheless supported Gramlich's "consumer sovereignty" approach to the appraisal of social costs. He suggested that more attention should be paid to the way the responses were influenced by movements of real wages and real wealth during inflationary periods.

William Nordhaus doubted that the social cost function could be linear in inflation and unemployment, even though Gramlich could not establish nonlinearity in his regression using Gallup data. Intuition suggests that people are more averse to inflation at high rates of inflation and more averse to unemployment at high rates of unemployment. Such nonlinearity would push the optimal policy response toward compromise and away from full accommodation. Also, Nordhaus pointed to the literature on voting behavior as another source of information on public attitudes toward inflation and unemployment.

Franco Modigliani emphasized that Gramlich's results depended heavily on the assumed nonlinearity of the Phillips curve. That is a standard assumption in the literature, but he had not been able to verify it empirically, nor had other investigators. James Tobin noted that the case for accommodation rested on shocks that created vertical displacements of the Phillips curve; any shock that produced a horizontal displacement (as a strike might) would not call for accommodation.

A number of participants criticized the "robbery" analogy Gramlich had cited from Modigliani and Lucas Papademos. Tobin noted that the anticipated part of inflation would not generate such a transfer of wealth. Moreover, he pointed out that unemployment as well as inflation had distributional costs. The distributive costs of inflation should not be balanced against only the aggregative costs of unemployment.

Robert Gordon's comments on Gramlich's paper evoked some discussion. Kenen reminded Gordon that the appropriateness of any price index in a wage equation should not be judged by whether it yielded a vertical Phillips curve, but rather by goodness of fit and ability to predict outside the sample. Martin Baily felt that the growing scope of cost-of-living escalators, which Gordon had emphasized, argued for the consumer price index as the most promising candidate. Michael Wachter suggested that the growing reliance on cost-of-living allowances would shorten the lags in responses to fiscal and monetary policy, as compared with the lags found in equations fitted to historical data.

Other participants commented on William Fellner's credibility thesis. 
Walter Salant felt that Fellner might well be too optimistic in expecting people to unwind their inflationary expectations in three to five years. He noted that an entire generation had come of age with no experience of price stability. Considering how long it took a preceding generationwhose formative years had been spent in the depression of the thirties-to adjust to an environment of prosperity, Salant doubted that widespread expectations of inflation could be displaced in as few as five years, let alone in three. Duesenberry feared that a credible anti-inflationary policy could be a double-edged sword. Although some people might set lower prices assuming that prices and wages set by others were going to be lower, others might lower their demands for output in the expectation of a deep recession. Thus while he agreed that the parameters would be influenced by a credible policy, he suggested that the result might be a more severe recession as well as less inflation.

Finally, Gramlich sought to qualify Fellner's antibiotic analogy. A person will continue taking antibiotics only if he trusts the doctor's judgment. If he does not-say, because he doubts that the doctor understands the inflationary disease-he may well refuse to take the painful unemployment medicine, and fire all doctors who prescribe it. That is why the Gallup poll results can become relevant. 